\title{
AVALIAÇÃO DAS ÁREAS COM FRAGILIDADE AMBIENTAL NA BACIA HIDROGRÁFICA DO RIBEIRÃO DO DESCAROÇADOR, PIRASSUNUNGA-SP
}

\section{ASSESSMENT OF AREAS WITH ENVIRONMENTAL FRAGILITY IN THE RIBEIRÃO DO DESCAROÇADOR WATERSHED, PIRASSUNUNGA-SP}

\section{Letícia Carlos Gaspari \\ Universidade Federal de São Carlos. Email: leticiagasparini@hotmail.co $\mathrm{m}$ \\ Juliana Keppe Zanini \\ Universidade Federal de São Carlos. Email: \\ juliana.k.zanini1@gmail.co $\mathrm{m}$}

\section{Diego Peruchi Trevisan}

Universidade Federal de São Carlos. Email: diego.peruchi@gmail.com

\section{Marcelo Yuji Tanaka}

Universidade Federal de São Carlos. Email: marcelo.tanaka1993@gmai I.com

\section{Luiz Eduardo Moschini}

Universidade Federal de São Carlos. Email: lemoschini@ufscar.br

\section{RESUMO}

O estudo de fragilidade ambiental auxilia na tomada de decisão e planejamento territorial, uma vez que analisa características e potencialidades locais de forma conjunta. Assim, o objetivo deste trabalho foi analisar a fragilidade ambiental na Bacia Hidrográfica do Ribeirão do Descaroçador no município de Pirassununga/SP. Para isso, foram utilizados Sistemas de Informações Geográficas (SIGs) para realizar o mapeamento da declividade, pedologia, geologia e uso e cobertura da terra, e com base nesses dados, o índice foi aplicado. Os resultados mostraram que a região apresenta boas características físicas e ambientais, porém, com predominância das atividades agrícolas, havendo uma tendência temporal de potencialização e crescimento da fragilidade ambiental, alterando sua paisagem e características naturais. Com isso, pode-se determinar que 43,72\% de áreas que apresentam o grau de fragilidade baixa e $39,11 \%$ com grau médio. As atividades agrícolas na região tendem a aumentar gradativamente o grau de fragilidade ambiental, devido suas características de retirada do solo, consequente perda da biodiversidade local, modificações na paisagem e solo, ou seja, interferindo diretamente na conservação e manutenção de serviços ambientais do ecossistema.

Palavras-chave: Ações antrópicas, Recursos naturais, Vulnerabilidade ambiental

\section{ABSTRACT}

The study of environmental fragility assists in decision making and territorial planning, since it analyzes local characteristics and potential jointly. Thus, this work aimed to analyze the environmental fragility in the Ribeirão do Descaroçador Watershed in the Pirassununga - SP municipality. For this, Geographic Information Systems (GIS) were used to map the slope, pedology, geology, and land use and coverage, and based on these data, the index was applied. The results showed that the region has good physical and environmental characteristics, however, with a predominance of agricultural activities, with a time trend of potentiation and growth of environmental fragility, changing its landscape and natural characteristics. With that, it can be determined that $43.72 \%$ of areas have a low degree of fragility and $39.11 \%$ with a medium degree. The Agricultural activities in the region tend to gradually increase the degree of environmental fragility, due to their characteristics of soil removal, consequent loss of local biodiversity, changes in the landscape and soil, that is, directly interfering in the conservation and maintenance of ecosystem services.

Keywords: Anthropogenic actions; Natural resources; Vulnerability Index 


\section{INTRODUÇÃO}

A estrutura da paisagem é modificada principalmente pelo resultado das interações a curto e longo prazo entre forças físicas, biológicas, políticas, econômicas e sociais, em decorrência das interações entre natureza e sociedade, as quais produzem uma configuração caracterizada pela fragmentação ou conexão entre seus elementos (GOERL et al., 2011; SILVA, 2014).

Os processos que alteram as relações ambientais que definem os usos e cobertura da terra, os quais influenciam no padrão espacial e estrutural das paisagens. Estes, quando não realizados de forma planejada, resultam na degradação dos habitats, na perda de solos e dos ecossistemas. Tais impactos negativos comprometem a estrutura das paisagens e consequentemente sua estabilidade ao modificarem negativamente o capital natural (DOS SANTOS, 2011; CHAICHI; DAIM, 2018).

O rápido crescimento da população humana, com projeção de 8 a 10.5 bilhões em 2050, (UNITED NATIONS, 2017) e a crescente demanda por terras agrícolas, são um dos principais fatores de modificações das paisagens naturais, as quais promovem a conversão das mesmas para paisagens agrícolas ou urbanas (HANSEN et al., 2013).

Com o avanço tecnológico, científico e econômico, ocorre a mudança nos sistemas de produção e o cenário que se estabelece na sociedade, proporciona uma pressão sobre a utilização dos recursos naturais, modificando-os muitas vezes de forma irreversível, com consequente desequilíbrio ambiental. Dada a complexa inter-relação entre os componentes da natureza, tais como solo, relevo, clima, vegetação e recursos hídricos, qualquer alteração em um destes compartimentos, reflete-se sobre os demais componentes do sistema e ecológico (TIESKENS et al., 2017).

Com isso, o conhecimento do meio físico-social é fundamental para o planejamento dos diversos usos da terra, sejam eles rurais ou urbanos, por meio de estudos que possibilitem o diagnóstico ambiental, como afirma Christofoletti (2005): "A realização de análise ambiental, considerando as transformações possíveis em função dos projetos de uso do solo, nas suas diversas categorias, é exigência que se encaixa como medida preliminar, em face da política de desenvolvimento sustentável”.

Segundo Santos e Oliveira (2013), nos estudos de análise do meio socioambiental, com destaque em estudos geoambientais, é necessário conhecer o ambiente na sua totalidade, considerando todos os aspectos que interferem ou podem interferir neste. Assim, é fundamental, determinar uma categoria de diagnóstico geográfico, constituindo o geossistema como unidade de análise ideal. Para Bertrand (2004), o geossistema é uma unidade da paisagem que é consequência da combinação dinâmica de fatores do potencial ecológico, da exploração biológica e de ação antrópica.

Dessa maneira, o conceito de espaço geográfico, da forma como ele é construído, estruturado 
e organizado, traduz-se nas análises de paisagens. A crescente demanda de conhecimento científico sobre a realidade de espaços geográficos fez com que surgissem ferramentas de auxílio e de apoio significativo para tomada de decisão, tais como os Sistemas de Informações Geográficas (SIGs) (FITZ, 2008; TAVARES et al., 2017).

A fragilidade ambiental é um instrumento para analisar as condições de um determinado ambiente. Tamanini (2008) apresenta o conceito de fragilidade ambiental como sendo a vulnerabilidade do ambiente em sofrer qualquer tipo de impacto, levando em consideração as condições naturais, como declividade, cobertura vegetal, tipo de solo, entre outros, e, também, as condições antrópicas e usos da terra. Segundo Ross (1994), o estudo sobre fragilidade ambiental é um instrumento que auxilia de maneira significativa no planejamento ambiental, visando o desenvolvimento sustentável.

Logo, o conceito de fragilidade ambiental é importante para identificar áreas que carecem de maior proteção e necessitam de ações peculiares para a gestão de órgãos públicos. Diante disso, estudos de fragilidade ambiental em bacias hidrográficas são de extrema importância para o gerenciamento adequado desta, visando sua conservação e se necessário, métodos de restauração e auxiliam nas tomadas de decisões a fim de diminuir os impactos que ocupações irregulares podem causar, em locais que apresentam declividade acentuada ou solos inadequados para construções civis, por exemplo (ROSS, 1994; TREVISAN, MOSCHINI, 2016).

Desta forma, este trabalho teve como objetivo analisar a fragilidade ambiental da Bacia Hidrográfica do Ribeirão do Descaroçador no município de Pirassununga - SP por meio integração de suas características ambientais.

\section{METODOLOGIA}

\section{1 Área de estudo}

A área de estudo compreende a Bacia Hidrográfica do Ribeirão do Descaroçador localizada no município de Pirassununga/SP (Figura 1), nas coordenadas geográficas 21 59' 46" de latitude Sul e $47^{\circ} 25^{\prime} 33^{\prime \prime}$ de longitude Oeste, com uma área de drenagem de 727,11 km².

Segundo o serviço de Água e Esgoto - SAEP do município de Pirassununga e das informações do Instituto Brasileiro de Geografia e Estatística (IBGE, 2020), a água destinada para o centro urbano da cidade de Pirassununga é captada a partir da Bacia Hidrográfica Ribeirão do Descaroçador, o que torna a região uma importante área para análise das interferências e correlações das diferentes características da paisagem sobre a fragilidade dos ecossistemas naturais. 
Figura 1: Localização Geográfica da Bacia Hidrográfica do Ribeirão do Descaroçador, Pirassununga - SP

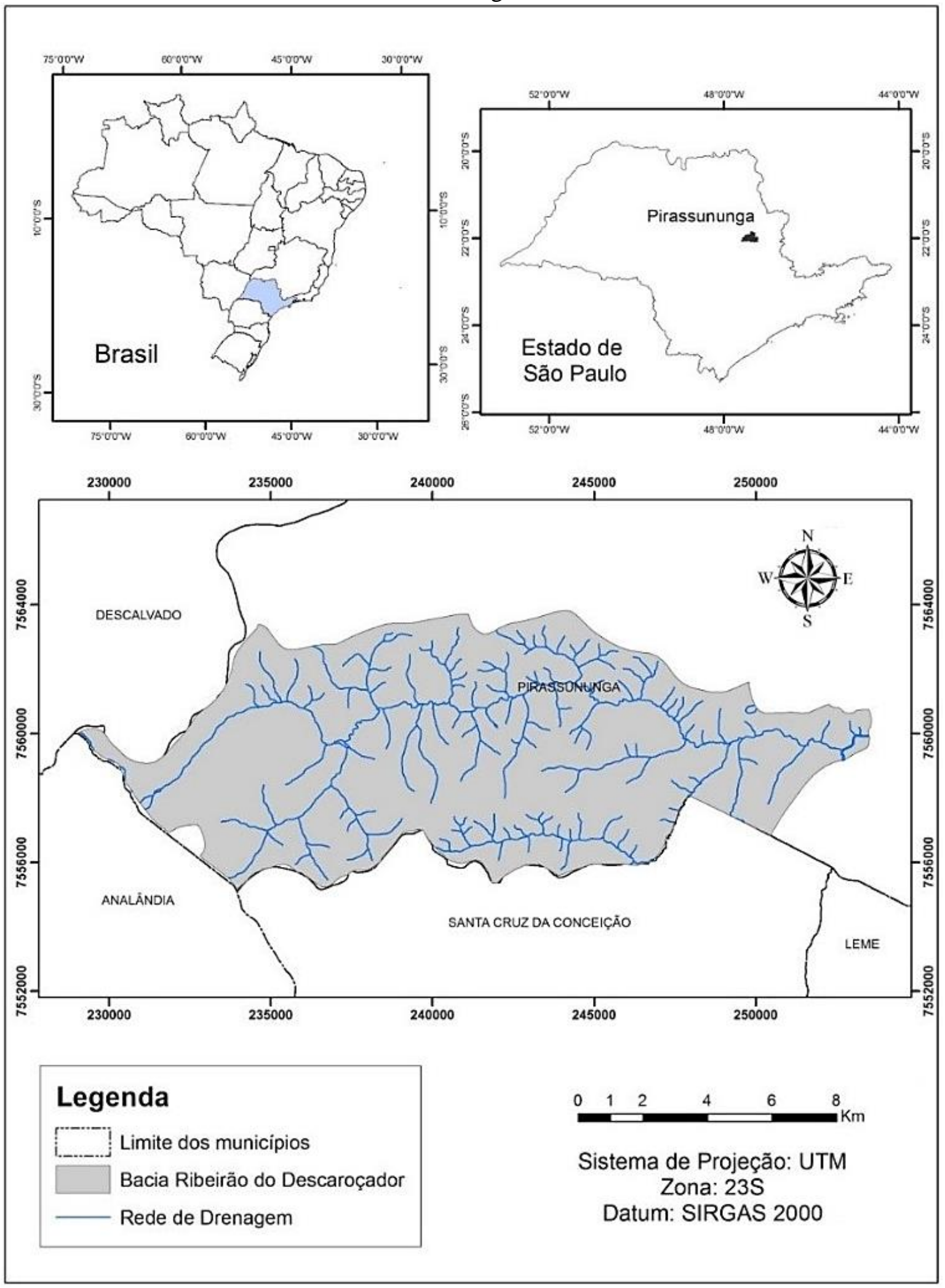

Fonte: elaboração dos autores 


\subsection{Métodos}

As informações foram elaboradas e georreferenciadas no software ArcGis 10.5, utilizando-se a projeção geográfica Universal Transversal de Mercator (UTM) Fuso 23 Sul, Datum horizontal SIRGAS2000, sendo utilizadas as cartas topográficas do IBGE, folhas: Descalvado (SF-23-V-C-IV4), Pirassununga (SF-23-V-C-V-3), Casa Branca (SF-23-V-C-V-4) Corumbataí (SF-23-Y-A-1-2) Leme (23-Y-A-II-1) e Rio Capetinga (SF-23-Y-A-II-2).

Para aplicação do índice de fragilidade ambiental foram consideradas as informações de geologia, pedologia, declividade e uso e cobertura da terra de 2017, conforme descrito abaixo. As informações foram agrupadas em 5 classes: muito baixa, baixa, média, alta e muito alta, sendo atribuídos a cada classe um valor de 1 a 5 , conforme os critérios qualitativos adaptados da metodologia desenvolvida por Silva (2014) e Trevisan e Moschini (2016).

O mapa temático de declividade foi gerado como base nas classes hipsométricas adquiridas das cartas topográficas do IBGE, por meio da função Slope no software ArcMap 10.5, sendo a declividade classificada de acordo com metodologia proposta por ROSS (1994) (Tabela 1).

Tabela 1: Categorias hierárquicas das classes de declividade

\section{Declividade}

Peso

Formas de topos com planos com drenagem de fraco entalhamento. Declividade até $6 \%$

1: Muito Fraca

Formas de topos planos ou ligeiramente convexidades com canais de drenagem de fraco entalhamento. Declividade entre 6\% a $12 \%$

2: Fraca

Formas de topos convexos de pequena dimensão inter fluvial e canais pouco entalhados e formas de topo convexos ou plano de dimensão inter fluvial pouco maior e canais medianamente entalhados. Declividade entre $12^{\mathrm{a}} 20 \%$

3: Média

Formas com topos planos e convexos e amplos com canais de forte entalhamento.

Declividade entre 20 a $30 \%$

Formas de topos aguçados ou convexos de dimensões inter fluviais de média a pequena e forte entalhamento dos canais. Declividade acima de $30 \%$

5: Muito Alta Fonte: ROSS (1994)

O mapa temático de geologia foi desenvolvido por meio das informações fornecidas pelo Instituto Geológico, vinculado à Secretaria do Meio Ambiente em escala 1:75.000 e categorizadas de acordo com a Tabela 2.

Tabela 2: Categorias hierárquicas de geologia

\begin{tabular}{cc}
\hline Geologia & Peso \\
\hline Formação Serra Geral, intrusivas básicas & 1: Muito fraca
\end{tabular}




$\begin{array}{cc}\text { Formação Serra Geral } & \text { 2: Fraca } \\ \text { Formação Corumbataí } & \text { 2: Fraca } \\ \text { Formação Piramboia } & \text { 3:Média } \\ \text { Aluviões } & \text { 5: Muito forte }\end{array}$

Fonte: Silva (2014).

O mapa temático de pedologia foi desenvolvido por meio das informações fornecidas pela Carta Pedológica do Estado de São Paulo (1999) realizada pelo Instituto Agronômico (IAC), na escala 1:500.000, sendo categorizadas conforme os tipos de solo de acordo com a Tabela 3.

Tabela 3: Categorias hierárquicas de pedologia

\begin{tabular}{cc}
\hline Pedologia & Peso \\
\hline Latossolo Vermelho & 1:Muito fraca \\
Latossolo Vermelho - Amarelo & 2: Fraca \\
Argissolo & 3: Média \\
Neossolo Litólico & 5:Muito forte \\
\hline
\end{tabular}

Fonte: ROSS (1994) e SILVA (2014).

Para a elaboração das informações de uso e cobertura da terra (Tabela 4), foi utilizada a imagem do satélite LandSat 8 disponibilizada pelo serviço Americano Geológico (USGS) - Earth Explorer, bandas 6/5/4, datada em 22 de abril de 2017, referente a órbita/ponto 220/75 que corresponde a área de estudo. A classificação dos usos foi realizada com base no sistema multinível de classificação proposto pelo Manual Técnico de Uso da Terra (IBGE, 2013).

Tabela 4: Categorias hierárquicas de uso de cobertura da terra

\begin{tabular}{lc}
\hline \multicolumn{1}{c}{ Uso e cobertura da terra } & Peso \\
\hline Florestas - Matas Naturais, Florestas cultivadas com biodiversidade & 1: Muito Fraca \\
Formações arbustivas naturais com estrato herbáceo denso & 2: Fraca \\
$\begin{array}{l}\text { Cerrado denso, Capoeira, Mata homogênea, Pastagem cultivada com } \\
\text { baixo pisoteio de gado }\end{array}$ & 3: Média \\
$\begin{array}{l}\text { Cultivo de ciclo longo em curvas de nível como café, laranja, cana, } \\
\text { silvicultura }\end{array}$ & 4: Alta
\end{tabular}


Áreas desmatadas e queimadas recentemente, solo exposto, 5: Muito Alta terraplanagem

Fonte: Adaptado de ROSS, (1994).

Assim, a partir das características de cada parâmetro estudado, foi atribuído um peso específico e classificadas novamente de acordo com o grau de fragilidade, que é: 1 = Muito fraca, 2 = Fraca, 3 = Média, 4= Forte, 5= Muito alta), sendo aplicada a função Álgebra de Mapas no software ArcGis 10.5, conforme a equação transcrita por Silva (2014) e Trevisan; Moschini (2016).

$$
\text { Fragilidade ambiental }=(D * 0,30)+(G * 0,15)+(P * 0,20)+(U * 0,35)
$$

Em que: $\mathrm{D}=$ Declividade $; \mathrm{G}=$ Geologia $\mathrm{P}=$ Pedologia e $\mathrm{U}=$ Uso e cobertura da Terra

\section{RESULTADOS E DISCUSSÕES}

A declividade da Bacia do Ribeirão do Descaroçador foi representada por classes de intervalos 0 a 6\%, 6 a 12\%, 12 a 20\%, 20 a 30\%,> 30\%. Assim, foi possível verificar que a região possui $2,48 \mathrm{~km}^{2}(1,96 \%)$ de áreas de declividade maiores que 30\% (Figura 2), com predomínio da classe de 6-12\%, com área de $47 \mathrm{~km}^{2}$ (30,37\%).

Figura 2: Classes de declividades da Bacia Hidrográfica do Ribeirão do Descaroçador

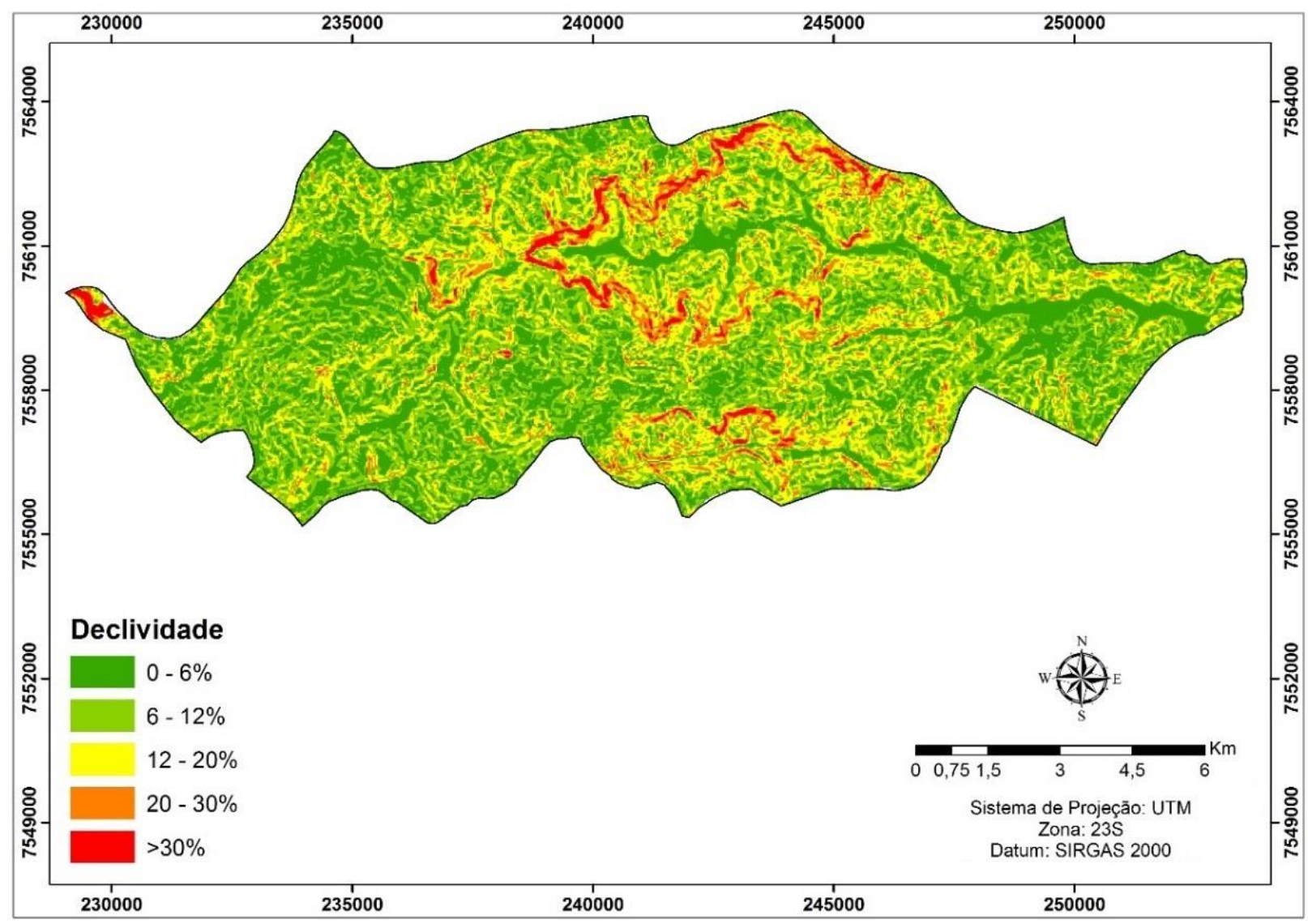

Fonte: Elaboração dos autores 
A topografia do terreno, principalmente a declividade, condiciona as atividades que na área se desenvolvem, sobretudo as atividades relacionadas à agricultura. Assim, tendo em vista que a região apresenta predominantemente a classe 6 - 12\% de declividade (Tabela 5), observa-se a área com um grande potencial para atividades agrícolas intensivas e com o uso de maquinário (TREVISAN et al., 2020).

Tabela 5: Distribuições das classes de declividade e seus respectivos valores e pesos

\begin{tabular}{cccc}
\hline Declividade & Fragilidade (Pesos) & Área $(\mathbf{k m})$ & Porcentagem \\
\hline $0-6 \%$ & 1 & 38,56 & 30,37 \\
$6-12 \%$ & 2 & 47,55 & 37,45 \\
$12-20 \%$ & 3 & 30,37 & 23,92 \\
$20-30 \%$ & 4 & 7,99 & 6,30 \\
$>30 \%$ & 5 & 2,48 & 1,96 \\
Total & - & $\mathbf{1 2 6 , 9 5}$ & $\mathbf{1 0 0 , 0 0}$ \\
\hline
\end{tabular}

Fonte: Elaboração dos autores

Para as classes pedológicas, a bacia hidrográfica está recoberta por quatro tipos de solo (Tabela 6 e Figura 3), onde mais de 65\% da área é composta de Latossolos (Latossolo Vermelho e Latossolo Vermelho - Amarelo).

Figura 3: Classes Pedológicas da Bacia Hidrográfica do Ribeirão do Descaroçador

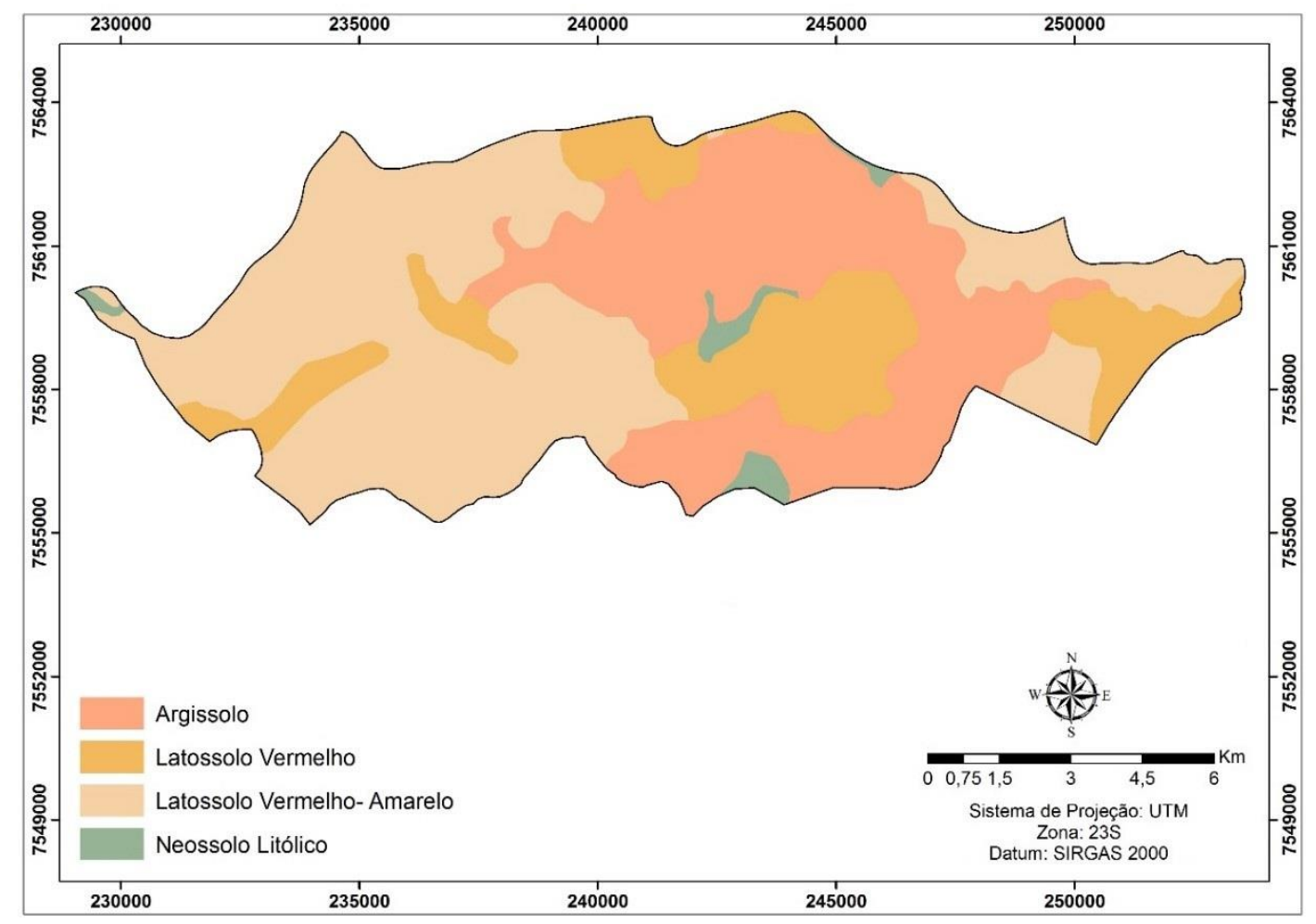

Fonte: Elaboração dos autores

Os latossolos, distribuem-se em áreas de relevo pouco acidentado, constituído por colinas amplas, ou nos topos aplainados, como as colinas médias e os morros. São solos com pouca 
diferenciação entre os horizontes, reconhecidos pela cor quase homogênea do solo com a profundidade (TAVARES et al., 2017) e normalmente, estão situados em relevo plano a suaveondulado, com declividade que dificilmente ultrapassa 7\%, sendo profundos, porosos, drenados, permeáveis e de fácil preparo (TEIXEIRA et al., 2000; TAVARES et al., 2017).

Tabela 6. Distribuição dos Tipos de solo e seus respectivos pesos.

\begin{tabular}{cccc}
\hline Pedologia & Fragilidade (Pesos) & Área $(\mathbf{k m})$ & Porcentagem \\
\hline Latossolo Vermelho & 1 & 24,31 & 19,10 \\
Latossolo Vermelho- Amarelo & 2 & 58,90 & 46,28 \\
Argissolo & 3 & 41,21 & 32,87 \\
Neossolo Litólico & 5 & 2,22 & 1,75 \\
Total & - & $\mathbf{1 2 6 , 9 5}$ & $\mathbf{1 0 0 , 0 0}$ \\
\hline
\end{tabular}

Fonte: Elaboração dos autores

A análise das classes geológicas da Bacia do Ribeirão do Descaroçador demonstrou cinco tipos distintos (Figura 4 e Tabela 7), sendo o principal deles a Formação Pirambóia, que tem grande importância na definição do Sistema Aquífero Guarani e com rochas que funcionam como reservatórios de óleo, produzido pelos folhetos pirobetuminosos da Formação Irati (CÔRTES; PERINOTTO, 2015). Além disso, a formação Piramboia é uma unidade litoestratigráfica da Bacia do Paraná, que se estende do estado do Paraná até o estado de São Paulo (CÔRTES; PERINOTTO, 2015).

Além disso, a segunda classe geológica que mais predomina na região é a Formação Corumbataí com $20 \%$ do total da área (Tabela 7), o que significa que os sedimentos são representados por siltitos e argilitos de cores rosadas, marrons, raramente esverdeadas (MASSOLI, 1983; CÔRTES E PERINOTTO, 2015).

Tabela 7: Distribuições das classes geológicas e seus respectivos valores e pesos.

\begin{tabular}{cccc}
\hline Geologia & Fragilidade (Pesos) & Área(km) & Porcentagem \\
\hline Formação Serra Geral & 1 & 15,18 & 11,96 \\
Formação Serra Geral & 2 & 0,31 & 0,25 \\
Formação Corumbataí & 2 & 25,40 & 20,01 \\
Formação Piramboia & 3 & 61,76 & 48,63
\end{tabular}


Revista Tecnologia e Ambiente, v. 26, 2020, Criciúma, Santa Catarina/SC ISSN Eletrônico 2358-9426 e ISSN Impresso 1413-8131

$\begin{array}{cccc}\text { Aluviões } & 5 & 24,30 & 19,16 \\ \text { Total } & - & \mathbf{1 2 6 , 9 5} & \mathbf{1 0 0 , 0 0}\end{array}$

Fonte: Elaboração dos autores

Figura 4: Classes geológicas da Bacia Hidrográfica do Ribeirão do Descaroçador

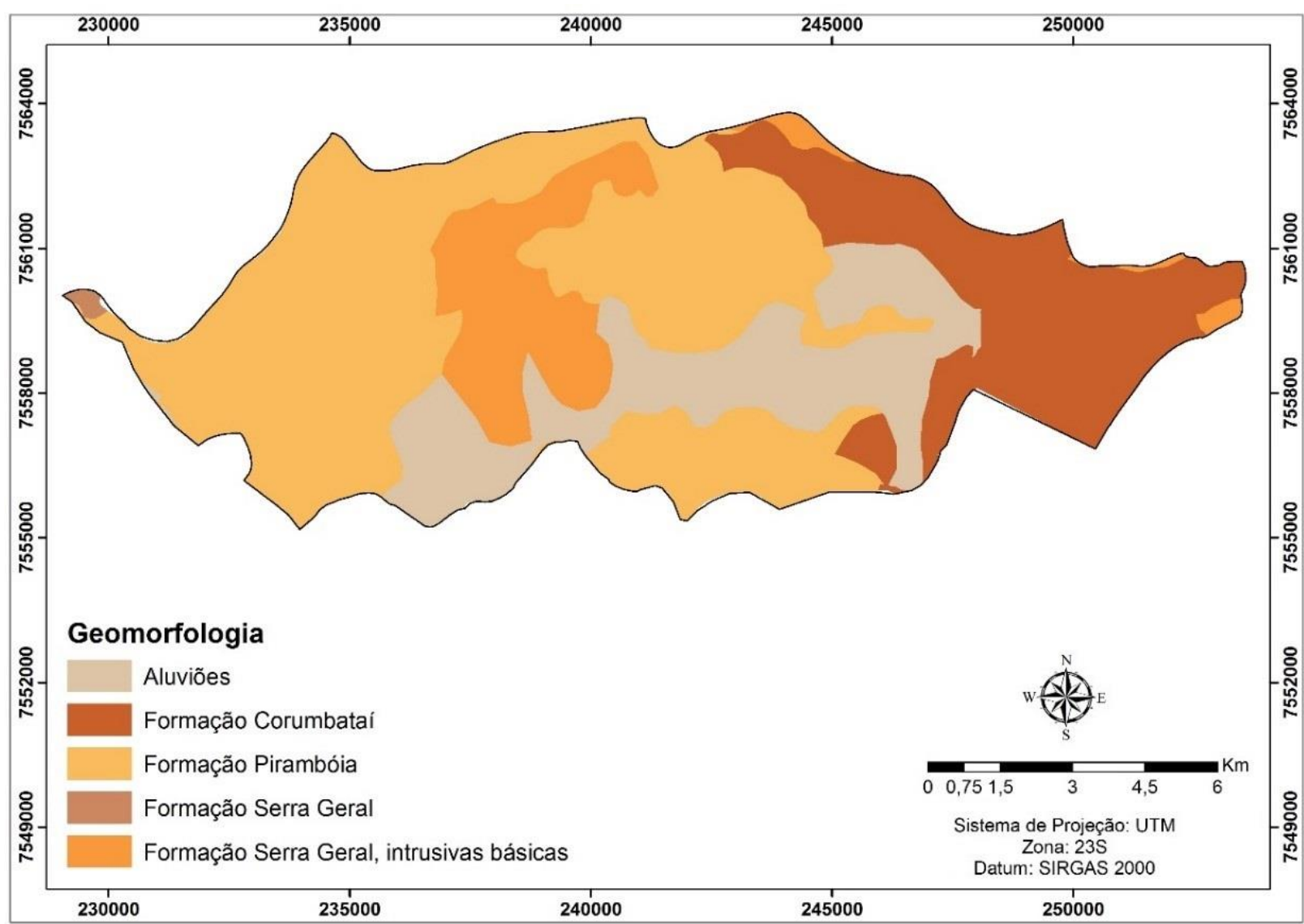

Fonte: Elaboração dos autores

A análise do uso e cobertura da terra demonstrou a predominância das áreas naturais $(36,03)$, com a classe vegetação nativa (Figura 5, Tabela 8), uma vez que a Bacia Hidrográfica do Ribeirão do Descaroçador se localiza predominantemente (90\%) na área rural do município de Pirassununga/SP, o que explica a baixa ocorrência da área urbanizada é tão baixa nesta bacia, representando apenas $1,38 \%$ da área total. 
Figura 5: Classes de uso e cobertura da terra da Bacia Hidrográfica do Ribeirão do Descaroçador

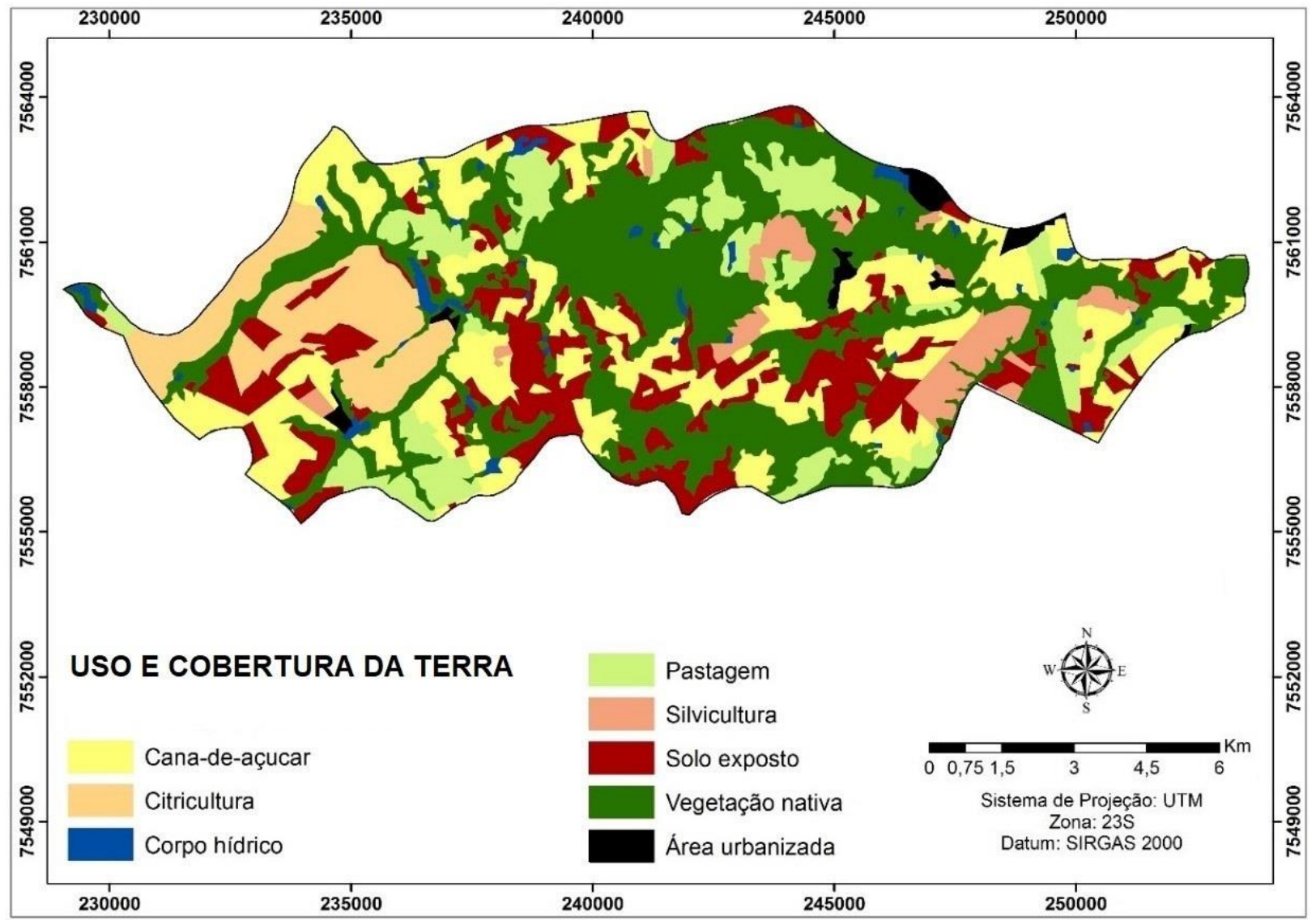

Fonte: Elaboração dos autores

Uma vez que, é possível observar a predominância das atividades agrícolas como plantio de cana-de-açúcar, solo exposto, citricultura e pastagem (Tabela 8). Uma vez que a região é uma área rural e a declividade do terreno apresenta características propícias ao tipo de atividade. A classe solo exposto, também predominante, apresenta-se como área de pousio para plantio de atividades agrícolas, principalmente do cultivo de cana-de-açúcar.

Tabela 8: Distribuições das classes de uso e ocupação e seus respectivos valores

Classes Tipos de uso Fragilidade (Pesos) Área $(\mathrm{km})$ Porcentagem

\begin{tabular}{ccccc}
\hline Área natural & Vegetação nativa & 1 & 45,75 & 36,03 \\
Água & Corpo hídrico & 1 & 1,73 & 1,36 \\
Área Antrópica agrícola & Pastagem & 3 & 12,71 & 10,01 \\
Área Antrópica agrícola & Cana-de-açúcar & 4 & 29,15 & 22,95 \\
Área Antrópica agrícola & Silvicultura & 4 & 5,01 & 3,94 \\
Área Antrópica agrícola & Citricultura & 4 & 10,62 & 8,36 \\
Área Antrópica não agrícola & Área urbanizada & 5 & 1,76 & 1,38
\end{tabular}




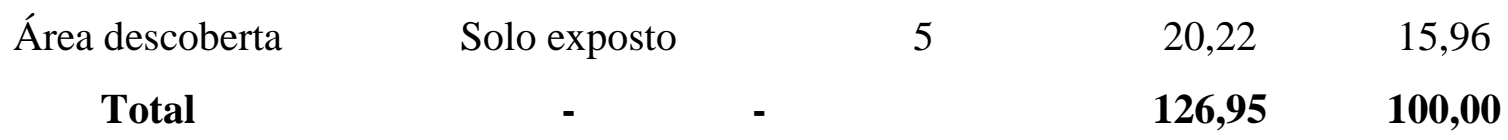

Fonte: Elaboração dos autores

Assim, por meio das informações levantadas e com o agrupamento destes, foi possível realizar o mapeamento e a atribuição de pesos para a classificação da fragilidade ambiental na Bacia Hidrográfica do Ribeirão do Descaroçador (Figura 6 e Tabela 9). Observou-se a predominância e concentração de $43,72 \%$ de áreas que apresentam o grau de fragilidade muito baixa, explicadas principalmente pela alta presença de áreas naturais e também pela predominância de baixas declividades na região.

Tabela 9: Distribuições das classes de Fragilidade

\begin{tabular}{cccc}
\hline Fragilidade & Fragilidade (Pesos) & Área $(\mathbf{k m})$ & Porcentagem \\
\hline Muito baixa & 1 & 13,99 & 11,04 \\
Baixa & 2 & 55,37 & 43,72 \\
Média & 3 & 49,54 & 39,11 \\
Alta & 4 & 7,63 & 6,02 \\
Muito alta & 5 & 0,45 & 0,10 \\
Total & - & $\mathbf{1 2 6 , 9 5}$ & $\mathbf{1 0 0 , 0 0}$ \\
\hline
\end{tabular}

Fonte: Elaboração dos autores

Apesar da presença predominante de Latossolos na área de estudo, os quais auxiliam na baixa fragilidade local devido suas características físicas, cerca de $39,11 \%$ da região apresenta grau de fragilidade média, o que é explicado pelas atividades agrícolas, que tem alto potencial de degradação ambiental, uma vez que tendem a retirar a vegetação nativa, tornando muitas vezes, o solo exposto, e, além disso, atividade de pastoreio também danificam o solo, aumentando gradativamente o grau de fragilidade da bacia.

Este cenário é também observado em outros estudos (PINATTI et.al, 2013; TREVISAN; MOSCHINI 2015 e TREVISAN; MOSCHINI 2016) os quais demonstram a perda da qualidade ambiental devido a expansão das fronteiras agrícolas, evidenciando a expansão do cultivo da canade-açúcar e a supressão de áreas de vegetação nativa além da substituição de outras práticas agrícolas. 
Figura 6: Classes de fragilidade ambiental da Bacia Hidrográfica do Ribeirão do Descaroçador

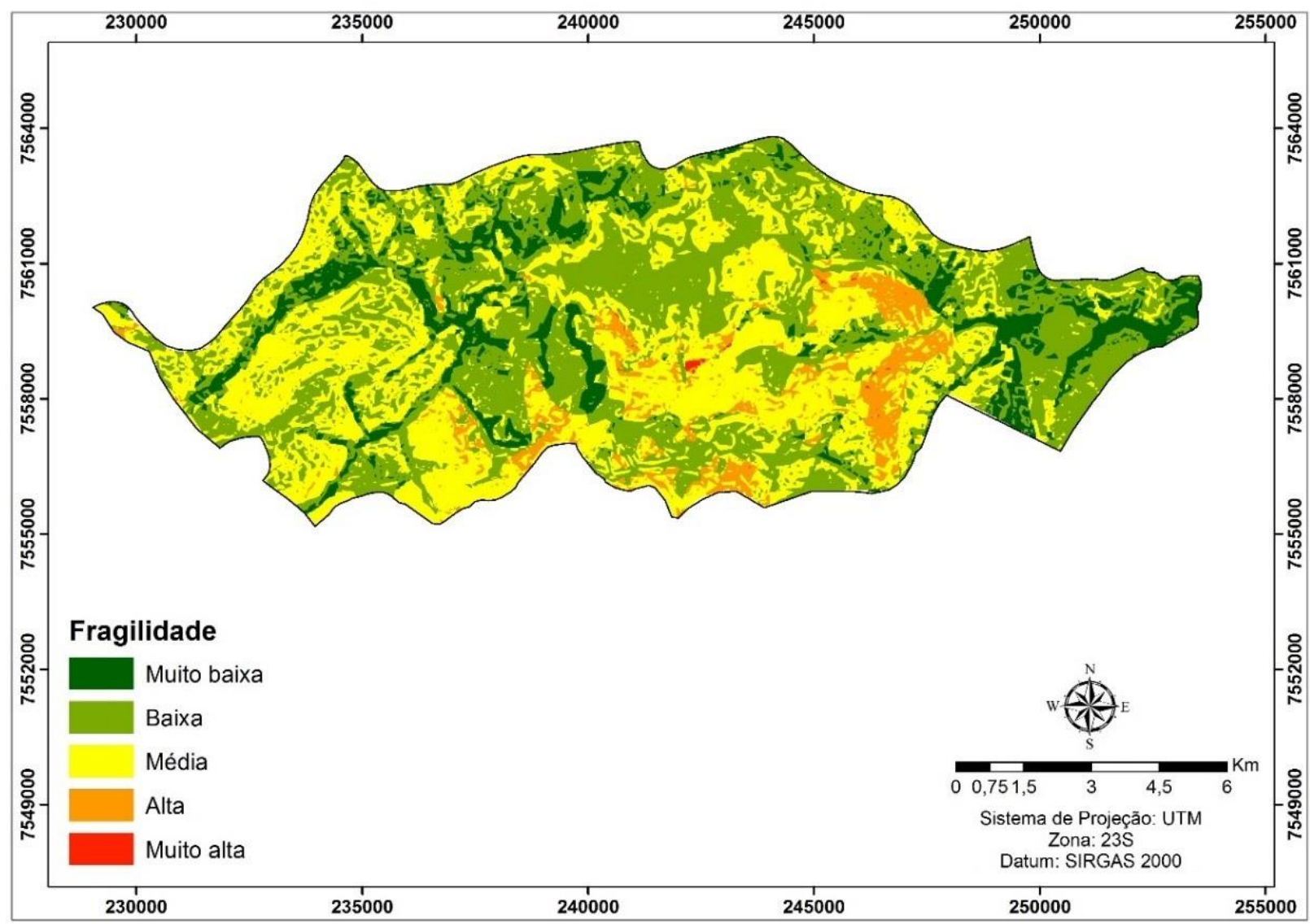

Fonte: Elaboração dos autores

O trabalho desenvolvido por Trevisan et al., (2018) objetivou avaliar a vulnerabilidade ambiental do município de São Carlos-SP, onde observou-se que:

\begin{abstract}
"as classes de baixa vulnerabilidade ambiental correlacionaram-se com as áreas de menores riscos aos efeitos da ocupação antrópica e as classes de alta vulnerabilidade ambiental correlacionaram-se com as áreas de altos riscos aos efeitos da ocupação antrópica. O grau de vulnerabilidade ambiental identificou principalmente valores baixos e médios de vulnerabilidade e o balanceamento dos pesos atribuídos as diferentes características da paisagem contribuíram de forma correlacionar os diversos compartimentos da paisagem sem considerar que uma ou outra característica possuiu maior influência em sua vulnerabilidade ambiental. As características ambientais de São Carlos contribuem para seu estado de vulnerabilidade que é potencializada principalmente pelas características econômicas ligadas as atividades agrícolas existentes na região."
\end{abstract}

\title{
4 CONSIDERAÇÕES FINAIS
}

O crescimento das atividades agrícolas da Bacia Hidrográfica do Ribeirão do Descaroçador pode aumentar o grau de fragilidade ambiental, devido aos diversos impactos como retirada do solo, 
perda da biodiversidade local e modificações na estrutura da paisagem, interferindo diretamente na conservação e manutenção de serviços ambientais proporcionados pelos ecossistemas.

Por meio do índice de fragilidade ambiental foi possível determinar o grau de conservação da região e interligá-las com as características físicas, bióticas e abióticas. A bacia hidrográfica apresenta predominantemente grau baixo de fragilidade ambiental, mas, observa-se crescimento das atividades agrícolas, o que pode vir a acarretar num aumento significativo do grau de fragilidade, modificando sua paisagem e características naturais. Por outro lado, poderão trazer benefícios econômicos para a região, mas vale ressaltar que devem ser tomadas medidas de proteção e conservação a fim de diminuir os impactos que essas atividades podem causar.

Desta forma, os estudos de Fragilidade ambiental apresentam-se como importantes ferramentas para identificação de áreas degradadas, áreas com intensas alterações antrópicas rurais ou urbanas, auxiliando nas tomadas de decisões e no planejamento ambiental, a fim de diminuir os impactos e a ocupação inadequada.

\section{AGRADECIMENTOS}

Os autores agradecem a Fundação de Apoio à Pesquisa do Estado de São Paulo pelo apoio financeiro a pesquisa nos processos 2015/19918-3.

\section{REFERENCIAS}

BERTRAND, G. Paisagem e geografia física global: esboço metodológico. RÁEGA, Curitiba, n. 8, p. 141-152, 2004.

CABRAL, J. B. P.; DA ROCHA, I. R. MARTINS, P. A.; DA ASSUNÇÃO, H. F.; BECEGATO, V. A. Mapeamento da fragilidade ambiental da bacia hidrográfica do Rio Doce $(\mathrm{GO})$, utilizando técnicas de geoprocessamento. Revista Internacional de Ciencia y Tecnología de la Información Geográfica - GeoFocus, nº11, p. 51- 69, 2011.

CHAICHI, N.; DAIM, T. U. Landscape Analysis: Connected Lighting System. Infrastructure and Technology Management, v.7, p.45-65, 2018.

CHRISTOFOLETTI, A. aplicabilidade dos conhecimentos geomorfológicos nos projetos de planejamento. In: GUERRA, A. J. T; CUNHA, S. B. (Org). Geomorfologia: uma atualização de bases e conceitos. 6. ed. Rio de Janeiro: Bertrand Brasil, 2005. p. 415 - 440.

CÔRTES, A. R. P.; PERINOTTO, J. A. J. Fácies e associação de fácies da Formação Piramboia na região de Descalvado (SP). Revista do Instituto de Geociências - USP. São Paulo, v.15, n.3-4, p.23-40, 2015.

DOS SANTOS, R. M. Padrão temporal e espacial das mudanças de usos da terra e cenários para a conservação da biodiversidade regional do município de São Félix do Araguaia, MT. 2011. 153f. Tese (Doutorado em Ecologia de Recursos Naturais) - Universidade Federal de São Carlos, São Carlos, 2011.

FITZ, P. R. Geoprocessamento sem complicação. São Paulo: Oficina de Textos, 2008, 160p.

GOERL, R. F.; SIEFERT, C. A. C.; SCHULTZ, G. B.; DOS SANTOS, C. S.; DOS SANTOS, I. Elaboração e aplicação de índices de fragmentação e conectividade da paisagem para análise de bacias hidrográficas. Revista Brasileira de Geografia Física, v.5, p.1000-1012, 2011.

GONÇALVES, G. G. G.; DANIEL, O.; COMUNELlO, E.; VITORINO, A. C. T.; ARAI, F. K. FLORESTA, Curitiba, PR, v. 41, n. 4, p. 797 - 808, 2011. 
HANSEN, M. C.; POTAPOV, P. V.; MOORE, R.; HANCHER, M.; TURUBANOVA, S. A.; TYUKAVINA, A.; THAU, D.; STEHMAN, S. V.; GOETZ, S. J.; LOVELAND, T. R.; KOMMAREDDY, A.; EGOROV, A.; CHINI, L.; JUSTICE, C. O.; TOWNSHEND, J. R. G. Highresolution global maps of 21rst-century forest cover change. Science, v.342, p.850-853, 2013.

IBGE. Instituto de Geografia e Estatística. Divisão territorial brasileiro e limites territoriais: IBGE cidades - $\quad$ Pirassununga, 2020. Disponível em: <https://cidades.ibge.gov.br/brasil/sp/pirassununga/panoramahttps://cidades.ibge.gov.br/brasil/sp/pi rassununga/panorama>. Acesso em 24 de março de 2020.

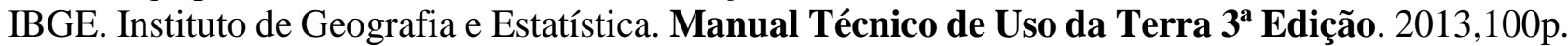
MASSOLI, M. Geologia da folha de Piraçununga, SP. Revista Instituto Geológico, v.4, p.25-51, 1983.

PINATTI, J. M.; MOSCHINI, L. E.; DOS SANTOS, R. M.; TREVISAN, D. P. Dinâmica da Paisagem da Zona de Amortecimento do Parque Estadual do Vassununga, SP. In: SANTOS, J.E.; ZANION, E.M. (Org.). Faces da Polissemia da Paisagem. 1ed.São Carlos, SP: Rima, 2013, v.5, p. 144-162.

ROSS, J. L. S. Análise empírica da fragilidade dos ambientes naturais e antropizados. Revista do Departamento de Geografia/FFLCH/USP, n. 8, p. 63-73, 1994

SAEP. Serviço de Água e Esgoto de Pirassununga. Pirassununga. Disponível em <http://www.saeppiras.com.br/http://www.saep-piras.com.br/ > Acesso em 11 de março de 2020.

SANTOS, J. G. OLIVEIRA, L. A. Fragilidade ambiental da bacia hidrográfica do Ribeirão Bento da Ressaca, município de Frutal - MG. OBSERVATORIUM: Revista Eletrônica de Geografia, v.5, n.15, p. 2-23, 2013.

SILVA, M. S. F., SOUZA R. M. Spatial patterns of forest fragmentation in the Flona Ibura - Sergipe. Mercator, v.13, n.3, p.121-137, 2014.

SILVA, V. C. B.; MACHADO, P. S. SIG na Análise Ambiental: Susceptibilidade Erosiva da Bacia Hidrográfica do Córrego Mutuca, Nova Lima - Minas Gerais. Revista de Geografia (Recife), v. 31, p.66-78, 2014.

TAMANINI, M. S. A. Diagnóstico físico-ambiental para determinação da fragilidade potencial e emergente da bacia do baixo curso do Rio Passaúna em Araucária - PR. 2008. 105 f. Dissertações (Mestrado em Geografia) - Universidade Federal do Paraná, Curitiba, 2008.

TAVARES, A. S.; JUNIOR, H. M.; SPALEVIC, V.; MINCATO, R. L. Modelos de erosão hídrica e tolerância das perdas de solo em latossolos distróficos no Sul de Minas Gerais. Revista do Departamento de Geografia, V. Especial, p.268-277, 2017.

TEIXEIRA, M. A.; MAGALHÃES, P. S. G.; BRAUNBECK, O. A. Equipamento para extração de amostras indeformadas de solo. Revista Brasileira de Ciência do Solo, v.24, n.4, p.693-699, 2000. TIESKENS, K. F.; SCHULP, C. J. E; LEVERS, C.; LIESKOVSKY, J.; KUEMMERLE, T.; PILENINGER, T.; VERBURG, P. H. Characterizing European cultural landscapes: Accounting for structure, management intensity and value of agricultural and forest landscapes. Land Use Policy, v.62, p.29-39, 2017.

TREVISAN, D. A; MOSCHINI, L. E. Determinação das áreas com fragilidade ambiental do município de São Carlos, São Paulo, Brasil. Geografia, Ensino e Pesquisa, v.20, n.3, p.159-167, 2016.

TREVISAN, D. P., BISPO, P. C., ALMEIDA, D., IMANI, M., BALZTER, H., MOSCHINI, L. E., 2020. Environmental vulnerability index: An evaluation of the water and the vegetation quality in a Brazilian Savanna and Seasonal Forest biome. Ecological Indicators, v.112, p.1 - 15.

TREVISAN, D. P.; MOSCHINI, L. E. Dinâmica de Uso e Cobertura da Terra em Paisagem no Interior do Estado de São Paulo: Subsídios para o planejamento. Fronteiras: Journal of social, technological and environmental science, v.4, p.16-30, 2015.

TREVISAN, D. P.; MOSCHINI, L. E.; DIAS, L. C. D.; GONCALVES, J. C. Avaliação da vulnerabilidade ambiental de São Carlos - SP. Revista Ra'e Ga, v.44, p. 272 -288, 2018. 
Revista Tecnologia e Ambiente, v. 26, 2020, Criciúma, Santa Catarina/SC ISSN Eletrônico 2358-9426 e ISSN Impresso 1413-8131

UNITED NATIONS. World Urbanization Prospects: The 2017 Revision. United Nations, New York, 2017, 300p. 